\title{
EXERGETIC ANALYSIS OF THE TRANSCRITICAL CYCLE OF AN BOTTLE COOLER OPERATING WITH $\mathrm{CO}_{2}$
}

\author{
Igor Marcel Gomes Almeida \\ Federal Institute of Education, Science and Technology of Rio Grande do Norte, Campus \\ Santa Cruz, Refrigeration Course Department \\ E-mail: igor.almeida@ifrn.edu.br \\ Cleiton Rubens Formiga Barbosa \\ Energy Laboratory, Departament of Mechanical Engineering, Federal University of Rio \\ Grande do Norte, Natal-RN \\ E-mail: cleiton@ufrnet.br \\ Francisco de Assis Oliveira Fontes \\ Energy Laboratory, Departament of Mechanical Engineering, Federal University of Rio \\ Grande do Norte, Natal-RN \\ E-mail: franciscofontes@uol.com.br
}

\section{ANÁLISE EXERGÉTICA DO CICLO TRANSCRÍTICO DE UM REFRIGERADOR DE GARRAFAS OPERANDO COM CO $\mathrm{CO}_{2}$}

\begin{abstract}
RESUMO
A segunda lei da termodinâmica trata da qualidade da energia. Mais especificamente, ela está preocupada com a degradação de energia durante um processo, a geração de entropia, e as perdas de oportunidade da realização de trabalho, o que oferece muita margem para melhorias. O objetivo deste trabalho é identificar os principais fatores que afetam a performance do sistema de refrigeração com $\mathrm{CO}_{2}$. Devido ao impacto global dos CFC's e HFC's o uso de refrigerantes naturais tem recebido atenção mundial. O refrigerante natural, dióxido de carbono $\left(\mathrm{CO}_{2} / \mathrm{R} 744\right)$ é promissor para uso em sistemas de refrigeração, especialmente no ciclo transcrítico. Uma análise exergética através do ciclo de um refrigerador de garrafas (expositor) adaptado para uso comercial com dióxido de carbono foi realizada onde as efetividades dos componentes do sistema foram estimadas e classificadas, permitindo direcionar os esforços para o aperfeiçoamento dos componentes do ciclo transcrítico. A análise revelou que o compressor e a válvula de expansão são as grandes fontes de perdas no sistema e, os esforços devem ser direcionados para o aprimoramento destes componentes.
\end{abstract}

PALAVRAS-CHAVE: análise exergética, dióxido de carbono, ciclo transcrítico, refrigerantes naturais. 


\begin{abstract}
The second law of thermodynamics deals with the quality of energy. More specifically, it is concerned with the degradation of energy during a process, the entropy generation, and the lost opportunities to do work; and it offers plenty of room for improvement. This paper aims to identify key factors that affect refrigeration system performance with $\mathrm{CO}_{2}$. Due to the impact of global warming of CFC's and HFC's, the use of natural refrigerants has received worldwide attention. The natural refrigerant, carbon dioxide $\left(\mathrm{CO}_{2} / \mathrm{R} 744\right)$ is promising for use in cooling systems, especially in the transcritical cycle. An exergetic analysis through the cycle of a bottle cooller (exposer) adapted for commercial use with carbon dioxide was carried out so that the effectiveness of the system components can be estimated and classified, allowing direct efforts to improve performance of components to the transcritical cycle. The analysis revealed that the compressor and expansion valve are the largest sources of losses in the system, and therefore, efforts should focus on improving these components.
\end{abstract}

KEYWORDS: exergetic analysis, carbon dioxide, transcritical cycle, natural refrigerants. 


\section{EXERGETIC ANALYSIS OF THE TRANSCRITICAL CYCLE OF AN BOTTLE COOLER OPERATING WITH $\mathrm{CO}_{2}$}

\section{INTRODUCTION}

The classical substances as hydrochlorofluorocarbons (HCFCs) and clorofluorcarbons (CFCs) used as working fluids in the vapour compression systems have to be replaced by new substances because of their ozone depletion potential and their greenhouse effect. Carbon dioxide $\left(\mathrm{CO}_{2} / \mathrm{R} 744\right)$ is non-toxic, non-flammable, has zero ozone depletion potential and negligible global warming potential as refrigerant, excellent heat transfer coefficients, compatibility with material of refrigeration system and very low cost. At high ambient temperature, the carbon dioxide refrigeration cycle is operating in transcritical mode and at high working pressure because of the specific thermodynamic properties of carbon dioxide (relatively low critical temperature and relatively high critical pressure), Yoon et al. (2004).

This paper developed three scientific concepts: exergy, environment and sustainable development. The relations between exergy and both energy and the environment makes ir clear that exergy is directly related to sustainable development (Dincer and Rosen, 2005). Many suggest that mitigating the environmental impact of energy resource utilization and achieving increased resource utilization efficiency are best addressed by considering exergy. By extension, since these topics are critical elements in achieving sustainable development, exergy also appears to provide the basis for developing comprehensive methodologies for sustainability. The exergy of an energy form or a substance is a measure of its usefulness or quality or potential to cause change.

Industrial ecology is an approach to designing industrial systems that promotes systems that are less damaging to the environment. Jelinsky et al. (1992) defines industrial ecology as a new approach for the design of products and processes and to implement strategies for sustainable industrial production systems. It is a concept that industrial systems are seen in interaction with the environment that surrounds it. The objective is to optimize the cycle of materials. Within this concept there is the focus turned to the "Design for Environment" within which they can draw a restructuring environment industrial systems, and search for sustainable production systems. Industrial ecology methods can beneficially incorporate exergy to provide more powerful tools. Exergy methods are important since they are useful for improving efficiency.

According to Yumrutas et al. (2002) thermodynamic processes in refrigeration systems release large amounts of heat to the environment. Heat transfer between the system and the surrounding environment takes place at a finite temperature difference, which is a major source of irreversibility for the cycle. The first law of thermodynamics deals with the quantity of energy and asserts that the energy cannot be created or destroyed. This law merely serves as a necessary tool for the quantification of energy during a process and offers no engineering challenges. The second law, however, deals with the quality of energy. Çengel and Boles (2005) argue that this law has proved to be a very powerful tool in the optimization of complex thermodynamic systems. More specifically, she is concerned with the degradation of energy during a process, the entropy generation, and the lost opportunities to do work. Exergy based second law analysis of various systems has become a very effective tool to measure system effectiveness and to design the system to 
maximize energy savings. Exergetic analysis of a complex system can be performed by analyzing the components of the system separately. Identifying the main sites of exergy destruction, shows the direction for potential improvements. As you know all real thermodynamic processes are irreversible. Recently, Yumrutas et al. (2002) developed a methodology for exergetic analysis of vapour compression refrigeration systems, indicating that the major causative factors of irreversibility in the refrigeration cycle include: friction and heat transfer across a finite temperature difference in the evaporator, compressor, condenser, refrigerant lines, pressure drops, subcooling and superheating, and heat gains in refrigerant lines. Brown and Domanski (2003) developed entropy generation methodology to compare the amounts of entropy generation in each of the primary system components, the analyses show that the $\mathrm{CO}_{2}$ residential air-conditioning system generate 63\% more entropy than the R-22 residential air-conditioning system. The biggest contributors to the lower $\mathrm{CO}_{2}$ performance are irreversibilities associated with the heat rejection process and the expansion related processes.

Based on the above experimental and simulation work, the aim of this work is to identify the main factors that affect $\mathrm{CO}_{2}$ system performance theoretically. For the analysis in question, will be used to cycle cooling system proposed by Cecchinato et al. (2006), which deals with the development of an R744 commercial single door bottle cooler that is cost competitive and matches the performance of a typical cost optimised R134a system. This paper is a case study of the second law applied to experimental equipment.

\section{THE BOTTLE COOLER TRANSCRITICAL CYCLE}

The transcritical refrigeration system proposed by Cecchinato et al. (2006) and object of analysis of this paper is a bottle cooler of 466 litres internal volume and 556 external volume. Figure 1 shows the tested bottle cooler.

This refrigeration system was re-designed to be adapted to $\mathrm{CO}_{2}$ refrigerant. In this first realisation the main purpose was to verify the possibility of using components easily available on the market, yet assuring the same energy efficiency as the traditional appliances. The data of operation of the cycle were obtained through the utilisation of the test procedure for continuous running test for household applications, where the compressor runs continuously, at least for 24 hours, until thermal equilibrium is established. Tests were also carried out with an internal electric load of $188 \mathrm{~W}$ to keep the compartment temperature of $\mathrm{CO}_{2}$ cabinet at $5^{\circ} \mathrm{C}$. The ambient temperature was fixed in $30^{\circ} \mathrm{C}$ and $55 \%$ relative humidity. Table 1 shows the results from the transcritical cycle obtained by Cecchinato et al. (2006). A ratio of the work or useful energy output of a system versus the amount of work or energy put in to the system as determined by using the same energy equivalents for energy in and out. Coefficient of Performance (COP) is used as a measure of the steady state performance or energy efficiency of heating, cooling, and refrigeration appliances. It is equal to the energy efficiency ratio (EER) divided by 3.412. The higher the COP, the more efficient the device. 


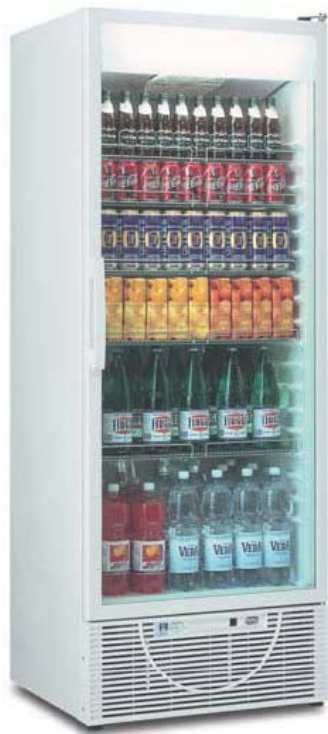

Figure 1 - The tested bottle cooler

Table 1: Values of the main variables of the transcritical cycle.

\begin{tabular}{|c|c|c|}
\hline Variables & Unit & $\mathbf{C O}_{\mathbf{2}}$ \\
\hline Heat load from electrical power & $\mathrm{W}$ & 188 \\
\hline Room temperature & ${ }^{\circ} \mathrm{C}$ & 28,8 \\
\hline Compartment mean temperature & ${ }^{\circ} \mathrm{C}$ & 5,2 \\
\hline Suction pressure & bar & 32,0 \\
\hline Evaporation sat. temperature (at compressor suction) & ${ }^{\circ} \mathrm{C}$ & $-3,2$ \\
\hline Discharge pressure & bar & 91,7 \\
\hline Condensation sat. temperature (at compressor discharge) & ${ }^{\circ} \mathrm{C}$ & - \\
\hline Discharge temperature & ${ }^{\circ} \mathrm{C}$ & 93,4 \\
\hline Gas cooler outlet temperature & ${ }^{\circ} \mathrm{C}$ & 33,7 \\
\hline Internal HEX high pressure outlet temperature & ${ }^{\circ} \mathrm{C}$ & 25,1 \\
\hline Evaporator outlet temperature & ${ }^{\circ} \mathrm{C}$ & 4,1 \\
\hline Internal HEX vapour outlet temperature & ${ }^{\circ} \mathrm{C}$ & 18,0 \\
\hline Suction temperature & ${ }^{\circ} \mathrm{C}$ & 18,8 \\
\hline Approach at gas cooler & ${ }^{\circ} \mathrm{C}$ & 4,9 \\
\hline Superheating at evaporator & ${ }^{\circ} \mathrm{C}$ & 7,3 \\
\hline Mass-flow rate & $\mathrm{kg} / \mathrm{h}$ & 8,7 \\
\hline Cooling capacity & $\mathrm{W}$ & 417 \\
\hline Compressor input energy & $\mathrm{W}$ & 293 \\
\hline Compression isentropic efficiency & - & 0,43 \\
\hline Coefficient of performance (COP) & - & 1,422 \\
\hline
\end{tabular}

The auxiliary computational tool for analysis of the system, the software CoolPack, is used for obtaining the P-h diagram and thermodynamic properties. In order to verify the results obtained by Cecchinato et al. (2006), the simulation of this cycle was performed with this software. Figure 2 shows the configuration of the transcritical cycle. The diagram of the cycle was obtained by the software, entering the parameters of the proposed system. 


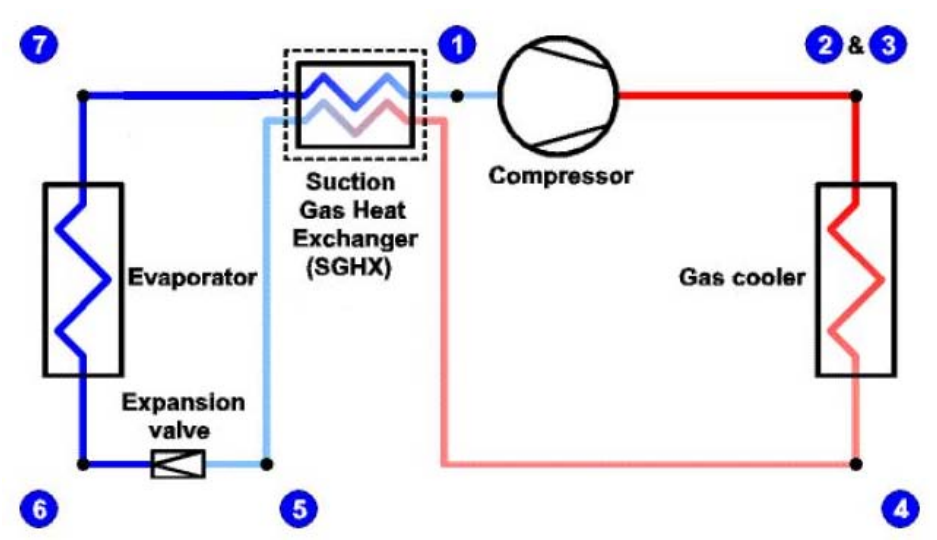

Figure 2 - The bottle cooler transcritical cycle

From state point (1) the suction gas is compressed by the compressor and discharged (2) \& (3). From the compressor the refrigerant is lead through a gas cooler. The refrigerant in the gas cooler outlet (4) is then lead to the "hot side" inlet of the suction gas heat exchanger (suction gas side is "cold side"), if this has been selected, or directly to the inlet of the expansion valve. From the "hot side" outlet of the suction gas heat exchanger (5) the refrigerant is expanded (6) into the evaporator. The evaporated and superheated refrigerant in the evaporator outlet (7) is then lead through the suction line to the "cold side" inlet of the suction of compressor (1). Figure 3 shows the P-h diagram of the bottle cooler cycle.

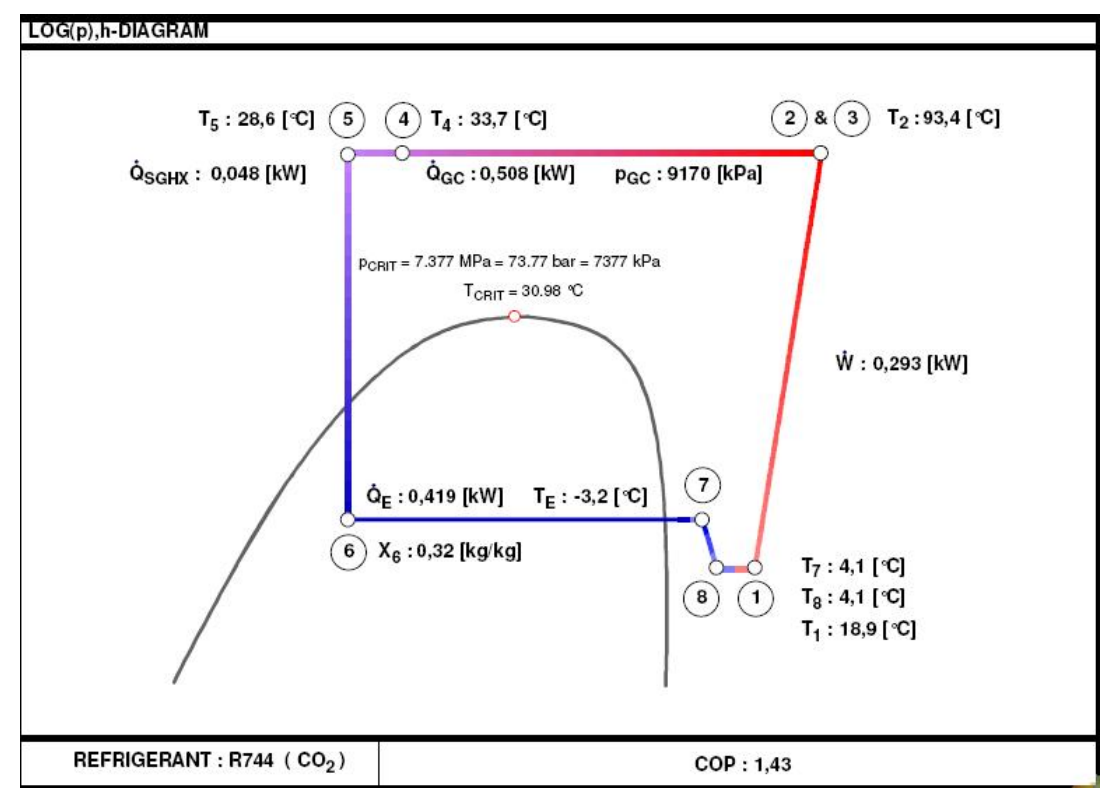

Figure 3 - P-h diagram

In the Figure 3, was not considered the existence of the pressure loss between state points 7 and 1 , and the existence of state point 8 was neglected, it is another heat exchanger that has been neglected in this analysis. The simulation using the CoolPack revealed that the compressor requires $293 \mathrm{~W}$ of work and $204 \mathrm{~W}$ lost to the environment in the form of heat (heat loss). Thus, the process of compression requires $89 \mathrm{~W}$ liquid power, this value has been used to determine the exergy loss of the compressor. Table 2 shows results of simulation in CoolPack. 
Table 2: Results of simulation with the software.

\begin{tabular}{|c|c|c|c|}
\hline Variables & Cecchinato et al.(2006) & CoolPack & Error (\%) \\
\hline Cooling capacity & $417 \mathrm{~W}$ & $419 \mathrm{~W}$ & 0,50 \\
\hline Heat transfer in the gas cooler & - & $508 \mathrm{~W}$ & - \\
\hline Compressor heat loss & - & $204 \mathrm{~W}$ & - \\
\hline Heat transfer in the SGHX & - & $48 \mathrm{~W}$ & - \\
\hline COP & 1,422 & 1,430 & 0,56 \\
\hline
\end{tabular}

The operating parameters obtained by use of software have little disagreement with respect to Cecchinato et al. (2006), however the error is negligible, which validates the application of computational tool in the analysis of thermal systems for cooling. Table 3 shows the thermodynamic properties of $\mathrm{CO}_{2}$ from CoolPack. The properties enthalpy and entropy calculated with the software will not be equal to those obtained with other programs, or taken from property any plots, if these programs and plots use a different reference condition.

Table 3: Thermodynamic properties of state points of transcritical cycle.

\begin{tabular}{|c|c|c|c|c|c|c|}
\hline State point & $\mathrm{T}\left({ }^{0} \mathrm{C}\right)$ & m (kg/s) & $\mathrm{x}(\%)$ & P (kPa) & h (kJ/kg) & s (kJ/kgK) \\
\hline 1 & 18,9 & 0,00241 & - & 3199 & 463,69 & 1,93139 \\
\hline $2 / 3$ & 93,4 & 0,00241 & - & 9170 & 500,49 & 1,97322 \\
\hline 4 & 33,7 & 0,00241 & - & 9170 & 290,08 & 1,28851 \\
\hline 5 & 28,6 & 0,00241 & - & 9170 & 270,16 & 1,20487 \\
\hline 6 & $-3,2$ & 0,00241 & 32,0 & 3199 & 270,16 & 1,24987 \\
\hline 7 & 4,1 & 0,00241 & - & 3199 & 443,89 & 1,90426 \\
\hline
\end{tabular}

\section{THERMODYNAMIC ANALYSIS}

For performing a thermodynamic analysis for $\mathrm{CO}_{2}$ cycle, the first law of thermodynamics is applied to the system. The first law of thermodynamics is a statement of the law of conservation of energy that readily yields the energy balance of the system,

$Q_{e}+W=Q_{g}$

equation (1)

were subscripts e and g represent the evaporator and gas cooler, respectively. The energy analysis of the cycle leads to computation of the Coefficient of Performance (COP), which indicates how efficiently energy is being used in the system. The COP is defined as the ratio of the desired heat transfer at the evaporator to the required work of the compressor,

$C O P=\frac{Q_{e}}{W}$

equation (2)

From the conservation of energy, the work and heat transfer at each component in a stationary open system can be determined by

$Q-W=\Delta H$

equation (3) 
The exergetic analysis will be performed based on the state points in table 3 . These state points are distinguished by of the determination of properties such as pressure, temperature and/or quality. The system was modeled based on exergy balance (second law) of the individual components of the system. To simplify the analysis were taken three hypothesys: compression process is adiabatic but not isentropic, isoenthalpic expansion, pressure drops in all the connecting pipes and heat transfer between the connecting pipes and the ambient are negligible.

The main purpose for an exergy analysis is to determine where and how losses occur so that energy may be used most effectively. The definition of exergy a pure substance is given by

$\psi=\left(h-h_{0}\right)-T_{0}\left(s-s_{0}\right)$

equation (4)

The terms $h_{0}$ and $s_{0}$ represent values of enthalpy and entropy at the environmental temperature $T_{0}$. Exergy is a combined property of the system and its environment. Dincer and Rosen (2005) argue that the properties of the reference environment, determine the exergy of a system or stream. Thus, it is of utmost importance define the condition of reference to simplify the mathematical model. For the present calculation it is taken as having a temperature of $298.15 \mathrm{~K}$ and a pressure of $101.3 \mathrm{kPa}$. The choice of reference temperature of $298.15 \mathrm{~K}$ simplifies the mathematical model, because the enthalpy and entropy of $\mathrm{CO}_{2}$ are zero in this condition (Srinivasan et al.,2003). For each component will be determined exergy loss, defined as

$\Delta \psi=$ exergy supplied - exergy recovered

equation (5)

and its exergetic effectiveness by

$\xi=$ exergy recovered / exergy supplied

equation (6)

Based on above, below follows the mathematical modelling in all components of cycle, in accordance with methodology suggested by Fartaj et al. (2004).

\section{A. COMPRESSOR}

The exergy supplied in the compressor is given by

$$
E_{\text {in }}=\dot{W}=\dot{m} \cdot\left(h_{2}-h_{1}\right)
$$

equation (7)

The exergy recovered in the compressor is given by

$\psi_{C}=\dot{m} \cdot\left(\psi_{1}-\psi_{2}\right)$

equation (8)

The exergy loss in the compressor is given by

$\Delta \psi_{C}=\psi_{1}+\dot{W}-\psi_{2}=E_{\text {in }}-\psi_{C}=\dot{m} \cdot\left(T_{0}\left(s_{2}-s_{1}\right)\right)$

equation (9) 
Where $\dot{m}$ is the mass flow rate of refrigerant in the cycle.

\section{B. EVAPORATOR}

The exergy supplied in the evaporator is given by

$$
\psi_{S}=\dot{Q}_{E}\left(1-\frac{T_{0}}{T_{r}}\right)
$$

The exergy recovered in the evaporator is given by

$$
\psi_{R}=\dot{m} \cdot\left(\psi_{7}-\psi_{6}\right)
$$

The exergy loss in the evaporator is given by

$$
\Delta \psi_{e v}=\psi_{7}+\dot{Q_{E}}\left(1-\frac{T_{0}}{T_{r}}\right)-\psi_{6}=\dot{m} \cdot\left(h_{7}-T_{0} s_{7}\right)+\dot{Q}_{E}\left(1-\frac{T_{0}}{T_{r}}\right)-\dot{m} \cdot\left(h_{6}-T_{0} s_{6}\right)
$$

The second term of the equation 12 is thermal exergy loss rate, where $\dot{Q}_{E}$ is heat absorbed in evaporator and $T_{r}$ is temperature at the boundary of component. According with Arora and Kaushik (2008) the thermal exergy loss rate is related to external irreversibility which takes place because of temperature difference between the control volume and the surroundings. If the system includes the immediate surroundings then the boundary of the thermal system is at the same temperature as the temperature of immediate surroundings and hence the value of thermal exergy loss turns out to be zero. In this case, the evaporation temperature is used, $\mathrm{CO}_{2}$ phase changes at constant temperature.

\section{EXPANSION VALVE}

$$
\Delta \psi_{V}=\dot{m} \cdot\left(\psi_{6}-\psi_{5}\right)=\dot{m} \cdot\left(T_{0}\left(s_{5}-s_{6}\right)\right)
$$

\section{GAS COOLER}

The exergy supplied in the gas cooler is given by

$$
\psi_{S}=\dot{m} \cdot\left(\psi_{2}-\psi_{4}\right)
$$

The exergy recovered in the gas cooler is given by

$$
\psi_{R}=\dot{Q}\left(1-\frac{T_{0}}{T_{G C}}\right)
$$

The exergy loss in the gas cooler is given by 


$$
\Delta \psi_{G C}=\psi_{2}-\dot{Q_{g}}\left(1-\frac{T_{0}}{T_{g c}}\right)-\psi_{4}=\dot{\dot{m}} \cdot\left(h_{2}-T_{0} s_{2}\right)-\dot{Q_{g}}\left(1-\frac{T_{0}}{T_{g c}}\right)-\dot{m} \cdot\left(h_{4}-T_{0} s_{4}\right) \quad \text { equation }(16)
$$

The gas cooler heat rejects to ambient by an amount $\dot{Q}_{g}$ at variable temperature (glide). For heat transfer occurring at variable temperature, Fartaj et al. (2004) uses the entropic average temperature. The entropic average temperature is often used to streamline and simplify the analyses of processes involving variable temperature heat transfer. It is defined as

$T_{g c}=\frac{h_{2}-h_{4}}{S_{2}-S_{4}}$

equation (17)

It is assumed that the heat $\dot{Q}_{g}$ is rejected to the cooling air at the constant temperature $T_{g c}$.

\section{E. INTERNAL HEAT EXCHANGER (SGHX)}

The exergy supplied in the internal heat exchanger is given by

$$
\Delta \psi_{S}=\dot{m} \cdot\left(\psi_{4}-\psi_{5}\right)
$$

The exergy recovered in the internal heat exchanger is given by

$$
\Delta \psi_{R}=\dot{m} \cdot\left(\psi_{1}-\psi_{7}\right)
$$

The exergy loss in the internal heat exchanger is given by

$$
\begin{aligned}
& \Delta \psi_{\text {HEX }}=\dot{m} \cdot\left(\left(\psi_{4}-\psi_{5}\right)-\left(\psi_{1}-\psi_{7}\right)\right)=\dot{m} \cdot\left(\left(h_{4}-h_{5}+T_{0}\left(s_{5}-s_{4}\right)\right)-\left(\left(h_{1}-h_{7}\right)+T_{0}\left(s_{7}-s_{1}\right)\right)\right) \\
& \text { equation (20) }
\end{aligned}
$$

To complement the analysis of irreversibilities in the transcritical cycle, is also an analysis performed by the entropy balance method in all components of the cycle. For the transcritical cycle operating with $\mathrm{CO}_{2}$, the entropy balance method can be deduced as follows

$$
\sum \delta S_{i}=\frac{Q_{g c}}{T_{a g c}}-\frac{Q_{e}}{T_{a e}}
$$

equation (21)

where $\delta S_{i}$ is the irreversible entropy increase in the system, $T_{a g c}$ and $T_{a e}$ are the average temperatures of the surroundings of gas cooler and evaporator, respectively, $Q_{g c}$ and $Q_{e}$ are the amounts of heat transfer in the gas cooler and evaporator. For each component, the irreversibilities can be identified

Gas cooler, $\delta S_{g c}=\frac{Q_{g c}}{T_{a g c}}-\frac{Q_{g c}}{T_{g c}}$

equation (22) 
Evaporator, $\delta S_{e}=\frac{Q_{e}}{T_{e}}-\frac{Q_{e}}{T_{a e}}$

equation (23)

Compressor, $\delta S_{c}=S_{2}-S_{1}$

equation (24)

Expansion valve, $\delta S_{e v}=S_{6}-S_{5}$

equation (25)

Internal heat exchanger, $\delta S_{s g h x}=\left(s_{5}+s_{1}\right)-\left(s_{4}+s_{7}\right)$

equation (26)

In the Eqs. 22 at 26, the first term of the difference represents the supplied entropy and the second term represents the recovered entropy. The values of the energy $Q(\mathrm{~kJ} / \mathrm{kg})$ in the gas cooler and evaporator in Eqs. 22, 23 and 24 consist in the values of table 4. The terms $T_{e}$ and $T_{g c}$ represents, respectively, the evaporation temperature and the entropic average temperature in the gas cooler.

\section{RESULTS AND DISCUSSIONS}

Table 4 shows the analysis of the transcritical cycle with the first law. Energy and mass balances were written around each components and combined with the thermodynamic properties to yield the results listed in the table using the Eq. (1), Eq. (2) and Eq. (3). The sum of the refigeration capacity (heat input in the evaporator) and the work consumed by the compressor is equal to the heat rejected at the gas cooler. The COP is defined as the ratio between cooling capacity and the work consumed in the compressor. In this case, $\mathrm{COP}=1,43$. It is noteworthy that for calculation of the COP was considered the work as being consumed in the compressor of $293 \mathrm{~W}$, which represents the total energy provided in this component, $204 \mathrm{~W}$ wasted in the form of heat loss and $89 \mathrm{~W}$ for the refrigerant compression.

Table 4: First law analysis of the transcritical cycle.

\begin{tabular}{|c|c|c|c|}
\hline Component & Energy Q (kJ/kg) & Energy Flow (W) & COP \\
\hline Compressor & 36,80 & 88,688 & - \\
\hline Gas Cooler & 210,67 & 507,714 & - \\
\hline Evaporator & 173,730 & 418,689 & - \\
\hline $\begin{array}{c}\text { Internal heat } \\
\text { exchanger }\end{array}$ & 19,660 & 47,381 & - \\
\hline System & - & - & 1,430 \\
\hline
\end{tabular}

The results of exergetic analysis are presented in Table 5. Column 1 shows the components of the order of the largest exergy loss (column 4). Columns 2 and 3 list the values of exergy supplied and recovered for each component of the transcritical cycle. An important parameter of evaluation is the exergetic effectiveness, which is defined as the ratio between the exergy recovered and exergy supplied. This parameter shows the difference between the performance of each component with respect to the ideal case. This result allows attention to be concentrated on the aspects of system operation that offer the greatest opportunities for improvement of the system performance (Fartaj et al, 2004). 
Analyzing the results, it appears that the compressor and expansion valve have the highest rates of exergy loss, approximately $60 \%$ of the total exergy loss. To improve performance of the cycle, special attention should be directed to the improvement these components, reducing the irreversibilities associated with the processes of compression and expansion, as the irreversibility lead to greater exergy destruction. The exergetic effectiveness indicates the degree of difficulty of improvement in the components. The compressor has more capacity for improvement in relation to the expansion valve, since the efficiency of the compressor is $66,0 \%$ and the valve is $86,9 \%$.

Because of the high pressure drop occurring in the system, the expansion device contributes a much larger fraction of the irreversibility compared to conventional systems (subcritical cycle). In the compressor, process irreversibility, pressure loss due to friction in inlet and outlet valves and heat loss to the environment are the basic reasons for the exergy loss in this component (Sarkar et al., 2005). In this evaluation, the heat loss through of the compressor, representing approximately $70 \%$ of total work supplied, is the main cause of high rate of exergy destruction in this component, being influenced also the low isoentropic efficiency of the compressor Danfoss TN1406. From viewpoint of the energetic efficiency, Cecchinato et al. (2006) says that the $\mathrm{CO}_{2}$ shows the worst performance when compared with the other two synthetic fluids: R134a and R404A. This worsening of energy efficiency is related to exergy losses during cyclic running, that penalise this fluid more than the competitors.

Looking at the gas cooler and evaporator, the irreversibility in components lead to substantial rates of exergy loss, mainly in the evaporator, occur mainly due to the difference in temperature between the heat exchangers and the surroundings. The effective temperature of the fluid in heat exchangers can be reduced and reduce consequently the irreversibility in these components, by increasing the area of heat transfer, fins may be incorporated or increase in the total length of the heat exchanger. The bottle cooler was redesigned to be adapted to R744 refrigerant, the original condensing finned coil was replaced by a more efficient one acting as gas cooler, having $2,69 \mathrm{~m}^{2}$ external heat transfer area. The increase in area, approximately $+32 \%$, was obtained with only $+11 \%$ increase in depth dimension and with the same face area. Two main reasons are considered to explain the low exergy loss of the gas cooler, the first relates to the entropic average temperature in this component is located close to environmental temperature, reducing the rate of irreversibility, the second is the improvement of the gas cooler used the experiment, approaching the optimum performance for this type of equipment. The internal heat exchanger/suction gas heat exchanger (SGHX) presented considerable exergy loss, this fact can be attributed to the difference in temperature between the sides of high and low pressure. Other relevant information is related to a constructive form of heat exchanger, because as cooling system is relatively small, the heat exchanger was obtained through physical contact between the pipes for high and low pressure with insulating material, it is important analyze the efficiency of this constructive form to achieve greater effectiveness of this component.

Table 5: Analysis of the transcritical cycle by exergy method.

\begin{tabular}{|c|c|c|c|c|}
\hline Component & $\begin{array}{c}\text { Exergy supplied } \\
\text { (W) }\end{array}$ & $\begin{array}{c}\text { Exergy recovered } \\
\text { (W) }\end{array}$ & $\begin{array}{c}\text { Exergy loss } \\
\text { (W) }\end{array}$ & $\begin{array}{c}\text { Effectiveness } \\
\text { (\%) }\end{array}$ \\
\hline Compressor & 88,688 & 58,618 & 30,07 & 66,0 \\
\hline
\end{tabular}




\begin{tabular}{|c|c|c|c|c|}
\hline $\begin{array}{c}\text { Expansion } \\
\text { valve }\end{array}$ & 246,996 & 214,663 & 32,33 & 86,9 \\
\hline Gas cooler & 13,700 & 12,900 & 0,870 & 94,1 \\
\hline Evaporator & 51,517 & 44,020 & 7,497 & 85,4 \\
\hline Internal HEX & 28,223 & 12,091 & 16,132 & 42,8 \\
\hline System & - & - & 86,899 & - \\
\hline
\end{tabular}

Figure 4 shows the exergy flow diagram, the consumption of exergy in the components of the transcritical cycle, illustrates the degradation of available energy (exergy) through the system. Can be observed that the compressor and expansion valve have the greatest losses of the total exergy loss of the system. The percentage values in the diagram were obtained through the relationship between exergy loss at each component and exergy supplied in the system $(88,688 \mathrm{~W})$. In a real process there will always be destructions and losses resulting in a greater exergy supplied into the process on the exergy of the product.

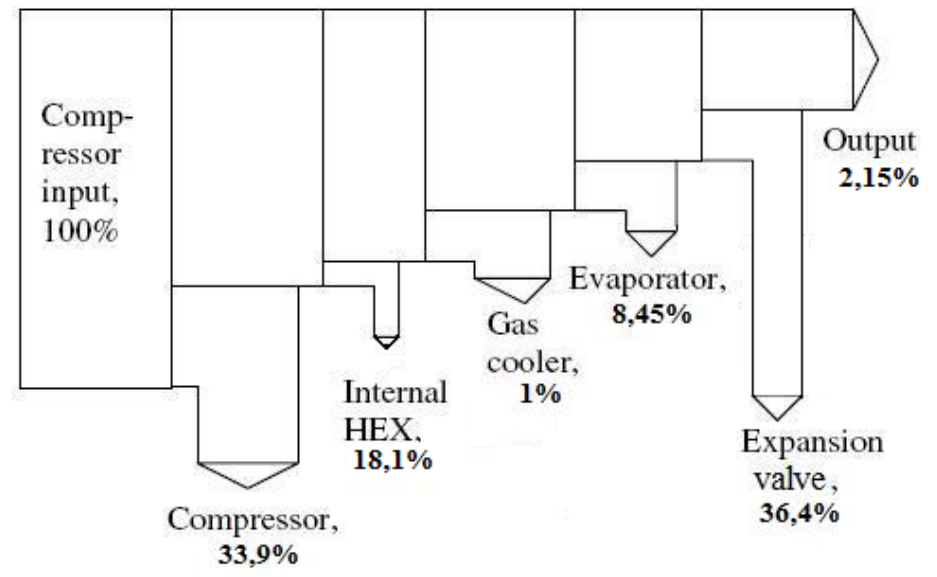

Figure 4 - Exergy flow diagram of the bottle cooler transcritical cycle.

Table 6 presents the results obtained from the entropy method. The results were obtained using the Eq. (22) at the Eq. (26). The fourth column lists the entropy increase in each component due to irreversibilities that exist in the real processes. The last column lists the contributions that are defined as the component entropy gain as a percentage of the total entropy gain in the system.

Table 6: Analysis of the transcritical cycle by entropy method.

\begin{tabular}{|c|c|c|c|c|}
\hline Component & $\begin{array}{c}\text { Entropy } \\
\text { supplied } \\
\text { (kJ/kgK) }\end{array}$ & $\begin{array}{c}\text { Entropy } \\
\text { recovered } \\
\mathbf{( k J / k g K )}\end{array}$ & $\begin{array}{c}\text { Entropy } \\
\text { increase } \\
\mathbf{( k J / k g K )}\end{array}$ & $\begin{array}{c}\text { Contribution } \\
\mathbf{( \% )}\end{array}$ \\
\hline Compressor & 1,97322 & 1,93139 & 0,04183 & 22,7 \\
\hline $\begin{array}{c}\text { Expansion } \\
\text { valve }\end{array}$ & 1,24987 & 1,20487 & 0,04500 & 24,4 \\
\hline Gas cooler & 0,70659 & 0,68555 & 0,02103 & 11,4 \\
\hline Evaporator & 0,64392 & 0,62447 & 0,01945 & 10,5 \\
\hline Internal HEX & 3,19277 & 3,13626 & 0,05651 & 30,7 \\
\hline System & 0,70659 & 0,62447 & 0,08212 & 100,0 \\
\hline
\end{tabular}

The results show that there is a discrepancy between the entropy increase for the system with the sum of the entropy in each components. This fact can be attributed to entropy 
generation that occurs in components (pressure drop, for example) that is not taken into account in the calculation through the system. The results for each component have the same trends of results for the method of exergy loss, where the expansion valve, compressor and heat exchanger internal present the highest values of entropy increase. Since the compressor and expansion valve are the bottlenecks for the development of this experimental system for improvements in the overall efficiency. Yang et al. (2005) performed an comparative study for the transcritical carbon dioxide refrigeration cycles with a throttling valve (without internal HEX) and with expander. It is found that ih the throttling valve cycle, the largest exergy loss occurs in the throttling valve, about $38 \%$ of the total cycle irreversibility With the application of the expander, the irreversibility loss of the expansion process is reduced almost by $50 \%$. The authors considered the isoentropic efficiency of the compressor as 75\%, to 43\% in this paper. Robinson and Groll (1998) presented two thermodynamic models for transcritical carbon dioxde cycles with and without an expansion turbine. The efficiencies of the transcritical carbon dioxide cycles will be compared with the ones of conventional R-22 cycles. The expansion valve is the component with the largest percentage of total irreversibility in the expansion valve carbon dioxide cycle. Replacing the expansion valve with an expansion work recovery turbine with an isentropic efficiency of $60 \%$ reduces the process's contribution to total cycle irreversibility by 35\%. Brown et al. (2002) evaluated performance merits of $\mathrm{CO}_{2}$ and R134a automotive air conditioning systems. The entropy generation calculations indicated that the large entropy generation in the gas cooler was the primary cause for the lower performance of $\mathrm{CO}_{2}$. The large $\mathrm{CO}_{2}$ temperature glide (approximately 80 versus $25^{\circ} \mathrm{C}$ for R134a) and the larger amount of heat needed to be rejected by the $\mathrm{CO}_{2}$ gas cooler than by the R134a condenser causes a significant amount of entropy generation.

\section{CONCLUSIONS}

The results of the analysis in transcritical cycle of an bottle cooler operating with $\mathrm{CO}_{2}$ led to the following conclusions :

a) As initial findings, the models proposed by Cecchinato et al. (2006) and Fartaj et al. (2004) are not based on design for the environment, as the proposed for Dincer and Rosen (2005).

b) The method of exergetic analysis applied in this work is not used from the viewpoint of evaluation of environmental impacts (industrial ecology), because it is a system of small size and unitary. This method was applied to detect and classify the irreversibilities and exergy losses that occur in the components of the transcritical cycle in order to promote improvements.

c) The mathematical model that was presented shown to be compatible with the system based on empirical data, results show that directions should be taken to improve the experimental model.

d) The simulation results with the software CoolPack show that $204 \mathrm{~W}$ is wasted as heat by the compressor, or approximately $70 \%$ of the work consumed by this component.

e) Compressor, expansion valve, internal heat exchanger and evaporator contribute to system exergy loss to a larger extent, while the gas cooler has a negligible effect. The expansion valve presents greater exergy loss because of the high pressure drop occurring in the system. 
f) The compressor, expansion valve and internal heat exchanger have the largest contributions to the entropy increase of the system. The compressor presents the largest capacity of improvements with respect to the expansion valve, since as presented exergetic effectiveness of $66 \%$, being more susceptible to improvements than the expansion valve.

g) The review of literature consolidates the compressor and expansion valve as the main sources of exergy losses in the transcritical cycle. Some authors indicates the gas cooler as larger irreversibility focus, such not verified in this paper.

h) Efforts should focus primarily on improving the compressor and expansion valve.

i) To improve the COP of the transcritical cycle of the R744 it is necessary both to optimize the components and to use some arrangements as the recovery of the compressio work and internal heat exchanger.

\section{REFERENCES}

1. ARORA, A., KAUSHIK, S.C., Theoretical analysis of a vapour compression refrigeration system with R502, R404 and R507A. International Journal of Refrigeration 31, 998-1005. 2008.

2. BROWN, J.S., DOMANSKI, P.A., Fundamental aspects of the application of carbon dioxide in comfort cooling. International Congress of Refrigeration, Washington, D.C. 2003.

3. BROWN, J.S., YANA-MOTTA, S.F., DOMANSKI, P.A., Comparitive analysis of an automotive air conditioning systems operating with CO2 and R134a. International Journal of Refrigeration 25, 19-32. 2002.

4. CECCHINATO, L., CORRADI, M., FORNASIERI, E., FOSSATI, C., ZILIO, C., Development of a transcritical R744 bottle cooler. 7th IIR Gustav Lorentzen Conference on Natural Working Fluids, Trondheim, Norway, May 28-31. 2006.

5. ÇENGEL, Y.A., BOLES, M., Thermodynamics: An Engineering Approach. Fifith Edition. McGraw-Hill. 2005. 1056 p.

6. DINCER, I., ROSEN, M.A., Exergy: Energy, Environment and Sustainable Development. Ed. Elsevier, 2005. 459 p.

7. FARTAJ, A., TING, D.S.K., YANG, W.W., Second law analysis of the transcritical CO2 refrigeration cycle. Energy Conversion and Management 45, 2269-2281. 2004.

8. JELINSKY, L.W., GRAEDEL, T.E., LAUDISE, R.D, McCALL, ., PATEL, C.K., Industrial ecology: concepts and approaches. Proceedings of the National Academy of Sciences of the USA 89, 793-797. 1992.

9. ROBINSON, D.M., GROLL, E.A., Efficiencies of transcritical CO2 cycles with and without an expansion turbine. International Journal of Refrigeration 21, 577-589. 1998.

10. SARKAR, J., BHATTACHARYYA, S., RAM GOPAL, M., Transcritical CO2 heat pump systems: exergy analysis including heat transfer and fluid flow effects. Energy Conversion and Management 46, 2053-2067. 2005.

11. SRINIVASAN, K., LIM, Y.K., HO, J.C., WIJEYSUNDERA. N.E., Exergetic analysis of carbon dioxide vapour compression refrigeration cycle using the new 
fundamental equation of state. Energy Conversion and Management 44, 3267-3278. 2003.

12. YOON, S.H., CHO, E.S., HWANG, Y.W., KIM, M.S., MIN, K., KIM, Y., Characteristics of evaporative heat transfer and pressure drop of carbon dioxide and correlation development. International Journal of Refrigeration 27, 111-119. 2004.

13. YANG, J.L., MA, Y.T, LI, M.X., GUAN, H.Q., Exergy analysis of transcritical carbon dioxide refrigeration cycle with an expander. Energy, 30, pp.1162-1175. 2005.

14. YUMRUTAS, R., KUNDUZ, M., KANOGLU, M., Exergy analysis of vapor compression refrigeration systems. Exergy 2, 266-272. 2002. 